\title{
Communicative Approach to Interactive Foreign Language Lesson at University
}

\author{
Alla Isakova* \\ Industrial University of Tyumen, Tyumen, Russia
}

\begin{abstract}
The article is devoted to communicative methods of the foreign language teaching, examining of reflexive practice and modelling of a communicative situation, conducting of an experimental study and revealing of a new teaching method efficiency. The communicative method based on the author's own teaching experience is analysed. The purpose of our experimental program is to define psychology and pedagogical conditions for empirical and theoretical model of communicative approach training in foreign languages training. The appeal of educational process focused training assumes change of ideas not only development of communicative abilities. The purpose of our experimental program is to define psychology and pedagogical conditions for empirical and theoretical model of communicative approach training in foreign languages training.
\end{abstract}

\section{Introduction}

The article purpose is to define tendencies of the main principles of a communicative and competence-based approach in a foreign language training. The appeal of educational process focused training assumes change of ideas not only in development of communicative abilities, skills, but also in high school education in general.

The purpose of our experimental program is to define psychology and pedagogical conditions for the empirical and theoretical model of communicative approach training in foreign languages training.

Profound learning and great teaching are ultimately predicated by the power of human relationships. This is a part of teaching both an art and science. We should teach students to think critically, manage own learning, collaborate and communicate effectively. Success breeds success [1].

Knowledge becomes contextualized and collectively constructed, therefore specific skills become less relevant than the meta-skills necessary to construct knowledge, including the diversity of thinking styles, collective intelligence, empathy, etc. "soft skills", such as collaboration, communication, or creative thinking, are increasingly needed for employability and successful career-building and vocational satisfaction as well as higher quality of life and deeper levels of citizenship participation and contribution [2].

Higher education supposes that students are taught in competent foreign-language communication by means of different types of foreign language speech activity: speaking, listening, reading, and writing [3].

Modern foreign-language education of higher school is accented on training grammatical correctly issued speech by means of communication, i.e. on grammar training in the course of communicative activity (learning by doing). From a pedagogical position, the teaching of the grammar of a foreign language is based on use of certain grammatical constructions (models) transmitting certain values, is considered as a process of understanding the meaning of the utterance through communication, close to real-life situations (real-life communication). Thus, in communicatively directed learning, the language is considered as "the system of expression of meaning, ensuring interaction and communication" (in communicatively directed learning [4].

There is no doubt that the linguistic component of the methods of teaching foreign languages is so strong that it inevitably leads to various transformations in the language personality. In this regard, the mentality becomes marginal. It is like the mentality of the diaspora [5], which forces us to pay closer attention to those internal processes in the language personality.

Economic globalization and political consolidation lead to the critical analysis of the traditional system of foreign-language education and development of other conceptual approaches in modern society [5].

At the present stage of the society development, specialists knowing several foreign languages are required. There is a linguistic modelling of the language personality in a situation of a profound learning of a foreign language.

Now Linguistic modelling is extremely demanded due to its explanatory power and the properties of language. So the construction of the evolution model of the language personality is promising and relevant in the process of foreign language teaching [6].

\footnotetext{
* Corresponding author: isakovaaa@yandex.ru
} 
Now it is difficult to call the system of Russian education conservative, nevertheless, higher education institutions try to keep the traditions, schools, so-called, classicality. On the one hand - the conservatism assumes remoteness from quickly developing public processes, on the other hand - protection from public upheavals, preservation of positive experience and established traditions.

Moreover, high school conservatism is compensated by different innovations as administrative character (for example, in the legal framework through the adoption of new curricula and programs) and methodological, i.e., the activities of those who participate directly in the educational process.

Current political, economic and social conditions put forward new requirements for the training of specialists in different areas, one of which is the mastering of foreign languages. The concept of foreign language mastering implies the ability to be a participant of the communication process in it. Touching upon the process of communication, we mean primarily oral communication, primary in relation to the writing. Teaching of a foreign language should be organized so that production would be in the leading place in the context of oral communication practices. Mastery of pronunciation and of any other didactical language material covers three levels: knowledge (and understanding), application and integration, as well as all didactical process components: teaching, learning, assessment, generalization. Students become negotiators between the self, the learning process and the object of learning [8].

The fact that classes in communicative approach are student-oriented does not rule out the importance of the teacher, who, in this case, is defined as a facilitator of language learning and an independent participant within the learning-teaching group [9].

The teacher is also perceived as a group process manager, analyst, and counsellor [10]. It should be emphasized that the teacher is not somebody who measures the capacities of the students in terms of the final product, but somebody who acts as a friend, coordinator, director, guide and counsellor [11].

Communicative competence is one of the basic characteristics of professional competence and professional training. Communicative competence is a synthesis of the social, perceptive, reflective, auto psychological, psychological and pedagogical competences, and related skills. The high level of development of the competence allows communicating effectively in a team of professionals in order to achieve their goals.

Communicative competence is developed through modelling of communicative situations and developing trainings, which help develop self-confidence, selfesteem, assertiveness, personal and social activity.

There are the following structural components of communicative competence: cognitive, regulatory, reflexive-status, and standard components. The cognitive component includes a high level of professional erudition, knowledge of applied communication strategies, methods of psychological influence, rules and techniques of rhetoric, polemic, reflective listening and so forth. Regulatory component - the ability to be engaged in dialogue, to persuade, to inspire, to change the communications tactics, to protect themselves from manipulation and psychological tricks, to take initiative in any kind of communications and situations. Reflective-status component - an attractive image, awareness of their status, opportunities and resources, a high level of reflective culture, allowing flexibility and respond to changes in the communicative situation.

Students with different levels of performance of the competent type of behaviour in communication, differ from each other at a statistically significant level for the development of personal qualities, indicating the personal conditioning of their communicative competence.

The highest direct correlations exist between the selfcontrol in communication and a number of characteristics of empathy as personal property. Without specifically organized support of such personality traits as empathy, internality, reflexive, assertiveness, and others, their formation in vocational education takes place only at the secondary level.

The development of communicative competence can be algorithmic based on the gradual formation of the individual components, education, integrative knowledge, skills and qualities.

The leading factor in the development is specially organized learning environment. The communicative competence process can be modern direction communicative competence's formation that is considered as the creation of a psychologist in the educational process of communicative situations that would run mechanisms for the development of the individual. In this case, we deal with the interactive teaching: expansion of joint work by the students, their communicative experience, primarily in the joint venture; the possibility to use not only the consciousness of man, but also his feelings, emotions; involvement in the learning process in order to provide comprehensive personal development.

Considering the fact that social competence involves skills for effective collaboration and partnership, especially, with regard to the second component, it is logical to assume that the social competence and the competence of the quality of the subject's activity includes the ability to prevent, resolve, and manage conflict situations that may arise in the course of interaction with other people.

Thus, we see that the communicative competence acts as a component of social competence. Based on the review of the definitions of social competence and communicative competence, we can imagine how important their role in the professionalization. The competences are synthesized, transformed and evolved long with the professionalization and the accumulation of life experience, and can be destroyed as a result of professional deformation. The professional development of the individual in professions is impossible without communicative competences.

The main methodological principle of the work is the principle of the anthropocentric approach to the language 
and speech. The leading method of the work relies on observation and experimentation techniques with subsequent analysis of empirical material. A descriptive, comparative method, a statistical method and psycholinguistic techniques were also used during the processing and analysis of the data.

The practical significance of the research is that the data of this work can be used at the lessons on a foreign language to increase the effectiveness of mastering foreign language speech.

Moreover, the results of the study can be used in special seminars on oral conversational speech, communicative behaviour and in the practice of teaching methods of foreign language teaching.

\section{The practice chapter}

\subsection{Review of new educational methods of innovations in foreign languages}

The development and implementation of new educational methods, including teaching methods, are one of the examples of innovations. However, immediately the question arises: Will new methods and methods of teaching become more effective, successful, practical, and more favourable for teaching practice than traditional ones. It is possible that the new method is characterized by a lower potential, and the negative consequences of its use can only be manifested after a few years. In this regard, new technologies should be checked at the stage of experimental research in the field of education, as in other spheres of public life.

At present, there is a high interest in the problems of the ethno-psycholinguistic level, which regards language as a reflection of sociocultural reality. It makes necessary to study the integral picture of the world and the cultural tradition. Modern answers to the questions "what to teach and how to teach", the methodology and the didactics of foreign languages teaching is looking for, studies analysing the correlation of language, speech and thought, thinking and communication, communicative and cognitive speech.

The principle of variability makes it possible for universities to choose any model of the pedagogical process, including author's. In these conditions, the teacher of a foreign language is given a certain freedom of creativity, freedom to choose innovative models and technologies of instruction. So, the modern educational process is inconceivable. Innovative phenomena. It gives a way to the specifics of the teacher's activity in modern conditions and transition from the knowledge paradigm of the pedagogical process to the individual. It means, from communicators - to the interactive methods of teaching.

Today the problem of foreign language teaching requires a systematic analysis of speech-activity from psycholinguistic, linguistic and psychological positions.

Traditional methods of foreign language teaching involve the assimilation of knowledge in artificial situations, because of which the future graduate does not see the connection of the subject under study with his future professional activity.

Table 1. Usage data of traditional methods of foreign language teaching.

\begin{tabular}{|c|c|}
\hline $\begin{array}{c}\text { Motivation of } \\
\text { foreign } \\
\text { language } \\
\text { learning }\end{array}$ & $\begin{array}{c}\text { Communicati } \\
\text { on with the } \\
\text { future } \\
\text { profession }\end{array}$ \\
\hline $76.00 \%$ & $58.00 \%$ \\
\hline
\end{tabular}

The most effective means of future graduates developing is simulation modelling. This training approach provides an imitation of professional activity elements, its typical and essential features. Its use makes possible to form skills and communication skills. It develops the habit of self-control, contributes to the real preparation for forthcoming activities and life in society. It helps to make foreign language lessons more lively, interesting, meaningful and gives the opportunity for students to express their own opinions more often and more often, express feelings, thoughts, assessments, ie. to think in a foreign language.

The following principles can be used as methods to improve the professional orientation of a foreign language studying: communication - dialogue about professional information in a foreign language, analysis of social and professional situations, fulfilment of creative assignments with profile content by students, game situations, role plays, quizzes.

As our experience shows, the practice of innovative technologies applying to improve the professional orientation of a foreign language studying is most noticeable when they are used in the system of studies, providing mastering a whole complex of skills, laying the effective basis for its effective profiling in life.

The main task of the conducted experimental research is to test the effectiveness of a new method of teaching a foreign language. From the scientific point of view, the effectiveness of the educational process is expressed in the development and growth of those competences of students (knowledge, skills, abilities) which have been defined as the educational purposes of training. Studies of the effectiveness of the new training method presuppose comparative-comparative work - the results of the new teaching method should be compared with the results of classical teaching. They should be tested in practice.

The new method can be recognized effective only when competences of the students studying by a new technique have a higher level.

\subsection{Modern communicative methods of our experimental program}

The purpose of our experimental program is to define psychology and pedagogical conditions for empirical and theoretical model of communicative approach in foreign languages training. The teacher focuses the student on understanding, perception, stimulates ability to make 
decisions on the basis of the accumulated experience of the cross-cultural relations, tolerances and reflections [4].

We will consider this communicative approach on the example of an interactive foreign language lesson.

The first level is encrypted methods and tools that stimulate awareness of communicative acts on a verbal and non-verbal level. Its purpose is to extract information on a given topic, to determine the level of knowledge in the group (empirically or reflectively), to predict the amount of knowledge that the teacher needs to give in an interactive lesson.

Table 2. The first level of our interactive lesson.

\begin{tabular}{|c|l|}
\hline Methods: & Conversation. \\
\hline Receptions: & reflection and clarifying questions. \\
\hline Means: & $\begin{array}{l}\text { literature, cinema, CD, musical } \\
\text { fragments, computer programs. }\end{array}$ \\
\hline Result: & $\begin{array}{l}\text { the teacher does not give full } \\
\text { information to students, students are } \\
\text { waiting for the topic, interactive } \\
\text { lesson in a foreign language. }\end{array}$ \\
\hline
\end{tabular}

The second level corresponds to the group aspect. This is the level of consistency and brevity. Its purpose is primary information. Students get acquainted with the elements of a cognitive object or phenomenon.

Table 3. The second level of our interactive lesson.

\begin{tabular}{|c|l|}
\hline Methods: & $\begin{array}{l}\text { exercise, a game exercise with a } \\
\text { didactic component, a game exercise } \\
\text { with a game component and an } \\
\text { autodidactic game. }\end{array}$ \\
\hline Reception: & $\begin{array}{l}\text { general issues, incentives, incentives, } \\
\text { directions, self-esteem. }\end{array}$ \\
\hline Means: & didactic materials. \\
\hline Result: & $\begin{array}{l}\text { students receive primary information } \\
\text { through a teaching game. Reflection } \\
\text { and clarifying questions }\end{array}$ \\
\hline
\end{tabular}

The third level assumes intellectual aspect, i.e. level of full information. The purpose is definition of the substantial and formal plan, understanding of a concrete object or phenomenon.

Table 4. The third level of our interactive lesson.

\begin{tabular}{|c|l|}
\hline Methods: & graphic modeling. \\
\hline Receptions: & $\begin{array}{l}\text { questions, explanation, education, } \\
\text { instruction, self-esteem. }\end{array}$ \\
\hline Means: & workbooks. \\
\hline Result: & $\begin{array}{l}\text { students use the means of the sign } \\
\text { system. }\end{array}$ \\
\hline
\end{tabular}

The fourth level corresponds to the personal aspect. Formally, this is the level of complete and clear information. The goal is to use communicative knowledge in interaction with the environment, stimulate real self-esteem among students, stimulate motivation, ability to self-assertion, etc.

Table 5. The fourth level of our interactive lesson.

\begin{tabular}{|c|l|}
\hline Methods: & $\begin{array}{l}\text { verbal logic task, game rules } \\
\text { assessment, creative approach, } \\
\text { diagnostic interview, psychological } \\
\text { games and other methods of knowledge } \\
\text { transfer. }\end{array}$ \\
\hline Reception: & questions, upbringing, self-esteem \\
\hline Means: & $\begin{array}{l}\text { didactic material, video film, computer } \\
\text { programs. }\end{array}$ \\
\hline Result: & $\begin{array}{l}\text { students have basic communicative } \\
\text { skills, are focused on solving problems, } \\
\text { are able to generalize and model the } \\
\text { studied material, to use the knowledge } \\
\text { gained in the practice of environmental } \\
\text { communication. }\end{array}$ \\
\hline
\end{tabular}

Thus, the use of a tiered, a communicative approach, interactive methods of foreign language teaching for reflective practice gives effective results and requires further study and approbation.

\section{Conclusion}

The epoch of globalization caused significant changes in the structure of the training of future specialists.

The development of high technologies, close scientific and technical relations require new approaches to the formation of a complex of competences, including, in particular, communicative and sociocultural in the framework of native and at least one or two foreign languages.

At present, the discipline "Foreign Language" is considered as an obligatory component of vocational training at the technic university. Modern higher professional education in the era of postmodernism is being reorganized due to modern requirements for specialists in conditions of academic mobility and global communication.

Modern communicative strategies create conditions for the development and constant measurement of the level of the formation of communicative competencies. Thus, communicative-oriented learning aims to teach future professionals of intercultural communication, using all the communication situations, tasks and specific examples necessary for it. The goal of the implementation of communicative strategies is the development of communicative competencies, which justifies the importance and the need to design the ideal image of what a student / pupil should be able to know and to become [12]. The attraction of cultural materials sharply increases the motivation of the teaching which is extremely important. The learning without motivation is ineffective. The materials of culture promote the awakening of cognitive motivation, i.e. students learn the program material and also get acquainted with unknown facts of culture, which undoubtedly causes their interest 
and contributes to the self-development of persons. The use of a tiered, communicative approach, interactive methods of foreign language teaching for reflective practice gives effective results and requires further study and approbation.

Modern university has made a decisive turn toward humanizing the process of teaching a foreign language. The personality of students, their needs, interests and characteristics are in the field of view of the teacher. This introduces significant adjustments to communication in a lesson, which is not built as an organization of individual speech actions or the exchange of communicative patterns but as an active interaction and cooperation of the teacher and students on the basis of students' methods of action.

However any interaction and furthermore program at design of a lesson assumes knowledge of psychological features of the partner in communication which naturally leads to an individualization of the learning process as a whole. Unfortunately, individualization is not fully realized in the practice of teaching. Most often it is limited to identifying and taking into account the individual traits of the trainees.

As a result, the teacher differentially approaches the development of training requirements, tasks, ways of activating students. At the same time, another, more important aspect of this process - the development of individual abilities and potential opportunities - is usually left without attention.

Thus, communicative approach to an interactive lesson is very important in the foreign language training at university. The main task of training in a foreign language is acquisition by students of language and communicative competence (speaking, audition, reading, the letter), level which allows to use a foreign language in professional practical and scientific activity. The interactive lesson gives a possibility of professional communication in a foreign language by students.

\section{References}

1. T. Beresford, Human-scale at scale human-scale at scale cultivating. New education cultures, Australia, Unit's School Design Lab, (2017)

2. P. Luksha, J. Cubista, A. Laszlo, M. Popovich, I. Ninenk, Educational ecosystems for societal transformation global education, Futures report, https://www.flickr.com/photos/acearchie/873884119 1). (2017)

3. S. D. Johnson, I. Wentling, E. Kalata, Illinois Low Enforcement Executive Forum, 45-59 (2002)

4. E. A. Karabutova, L. A. Kobzareva, L. N. Kolchinceva, Modern problems of science and education 1(1), 1064 (2015)

5. N. F. Alefirenko, Modern problems of the science of language (M.: Flinta, 2005)

6. A. A. Isakova, Integration of education 21(1-86), 46-53 (2017)
7. A.A. Isakova, Proceedings of the 7th International Scientific and Practical Conference Current Issues of Linguistics and Didactics, The Interdisciplinary Approach in Humanities (CILDIAH 2017) Advances in Social Science, Education and Humanities Research (ASSEHR) 97, 1-8. (2017)

8. M. P. Breen, C. N. Applied Linguistics 1(2), 89-110. (1980)

9. J. Basta, Facta universitaties, Series: Linguistics and Literature 9(2), 125-143 (2011)

10. J. C. Richards, Cooperative learning and second language teaching, (Cambridge, Cambridge University Press, 2006)

11. M. D. Cohen, K. Tellez, Bilingual Research Journal 18, 1-19 (1994)

12. J. Scrivener, Learning Teaching (Cambridge, Macmillan Books for Teachers, 2005) 